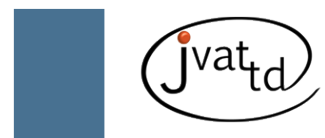

\title{
Epidemiological investigation on envenomation: from theory to practice
}

\author{
Chippaux JP $(1,2)$
}

(1) Center for the Study and Research of Malaria Associated with Pregnancy and Childhood (Cerpage), Cotonou, Benin; (2) Institute of Research for Development (IRD - UMR 216 "Mother and child facing tropical diseases"), Cotonou, Benin.

\begin{abstract}
A better understanding of the epidemiology of envenoming would improve care, provided that the survey is representative, reliable and accurate. Several types of surveys could help to clarify the incidence, severity, circumstances, factors and determinants of envenomations. The relevant information may be collected and analyzed from hospital records or case report forms (for retrospective studies) or established from a protocol of longitudinal observation of cases attended at health facilities during a given period (prospective study). The household survey includes interviewing all or part of the population of a locality with a standardized questionnaire to obtain information on the circumstances of the accident. Finally, standardized questionnaires can be administered to health workers in order to ascertain the circumstances and procedures of care, the availability and use of treatment and the level of knowledge of agents. Correctly performed, these surveys should promote the organization of the management of snakebites or scorpion stings because they identify the location of envenomation and quantify the needs. However, the surveyed localities should be chosen for relevance to be representative of the territory, just as methodology and analysis should be rigorous in order to give useful results.
\end{abstract}

Key words: epidemiology, snakebite, methodology, retrospective surveys, prospective surveys, household surveys.

Envenomation is a neglected public health problem worldwide, but especially in developing countries, particularly in Africa (1-3). A better understanding of the incidence and severity of envenomation, as well as the location of accidents and their circumstances, would probably improve snakebite management and help to allocate resources as needed (1).

However, case reporting is irregular or nonexistent, at least in developing countries, and the literature data are still insufficient.

I propose herein some simple and inexpensive methods in order to access enough reliable epidemiological data that would enable placement of sufficient amounts of antivenoms where they may be necessary, and to train health personnel.
Epidemiological methods described in this article stem from numerous studies cited in various published reviews (1-4). Some surveys have been carried out by several independent methods in order to compare the results and validate the methods: investigations in health centers, household surveys and/or surveillance in demographic sites where the population is followed longitudinally and provided notification of significant epidemiological events (5-11).

The methods used to study the epidemiology of envenomation or its management can be divided into three groups: investigations in health centers, household and community surveys, and surveys of health personnel in charge of management of bites or stings from venomous animals (Table 1). 
Table 1. Properties and characteristics of the different types of epidemiological studies regarding bites or stings by venomous animals

\begin{tabular}{|c|c|c|c|c|}
\hline Types of surveys & Advantages & Disadvantages & Expected results & Benefits \\
\hline $\begin{array}{l}\text { Retrospective } \\
\text { Health Center } \\
\text { surveys }\end{array}$ & $\begin{array}{l}\text { Rapidity; low } \\
\text { cost }\end{array}$ & $\begin{array}{l}\text { Missing data and } \\
\text { gaps; data about } \\
\text { outpatients not } \\
\text { recorded }\end{array}$ & $\begin{array}{l}\text { Hospital morbidity } \\
\text { and case fatality } \\
\text { rate }\end{array}$ & $\begin{array}{c}\text { Evaluation of } \\
\text { immediate } \\
\text { therapeutic needs }\end{array}$ \\
\hline $\begin{array}{l}\text { Prospective } \\
\text { Health Center } \\
\text { surveys }\end{array}$ & $\begin{array}{l}\text { Standardized } \\
\text { information } \\
\text { according to the } \\
\text { investigator }\end{array}$ & $\begin{array}{l}\text { Long; quite } \\
\text { expensive; } \\
\text { data about } \\
\text { outpatients not } \\
\text { recorded }\end{array}$ & $\begin{array}{l}\text { Hospital morbidity } \\
\text { and case fatality } \\
\text { rate; treatment } \\
\text { assessment; partial } \\
\text { identification of the } \\
\text { population at risk }\end{array}$ & $\begin{array}{l}\text { Improvement } \\
\text { of therapeutic } \\
\text { protocols }\end{array}$ \\
\hline $\begin{array}{l}\text { Household } \\
\text { surveys }\end{array}$ & Rapidity & Quite expensive & $\begin{array}{l}\text { General incidence } \\
\text { and mortality; } \\
\text { identification of } \\
\text { the population and } \\
\text { high-risk behaviors; } \\
\text { identification of } \\
\text { treatment-seeking } \\
\text { behavior }\end{array}$ & $\begin{array}{l}\text { Improvement of } \\
\text { epidemiological } \\
\text { knowledge; } \\
\text { completion and } \\
\text { extension of hospital } \\
\text { survey outcomes }\end{array}$ \\
\hline $\begin{array}{l}\text { Demographic } \\
\text { site surveys }\end{array}$ & $\begin{array}{l}\text { Standardized } \\
\text { information } \\
\text { according to the } \\
\text { investigator }\end{array}$ & $\begin{array}{l}\text { Long; quite } \\
\text { expensive; high } \\
\text { constraints on } \\
\text { populations }\end{array}$ & $\begin{array}{l}\text { General incidence } \\
\text { and mortality; } \\
\text { identification of } \\
\text { the population and } \\
\text { comportments at } \\
\text { risk; identification of } \\
\text { treatment-seeking } \\
\text { behavior }\end{array}$ & $\begin{array}{l}\text { Identical to } \\
\text { household surveys } \\
\text { with higher } \\
\text { precision and } \\
\text { reliability; crossing } \\
\text { with hospital data }\end{array}$ \\
\hline $\begin{array}{l}\text { Health } \\
\text { personnel } \\
\text { surveys }\end{array}$ & $\begin{array}{l}\text { Rapidity; low } \\
\text { cost }\end{array}$ & & $\begin{array}{l}\text { Modality of } \\
\text { patients' treatment; } \\
\text { symptom } \\
\text { confirmation; } \\
\text { overview on } \\
\text { practical knowledge } \\
\text { of health personnel; } \\
\text { identification of } \\
\text { training needs }\end{array}$ & $\begin{array}{l}\text { Improvement } \\
\text { of treatment } \\
\text { management }\end{array}$ \\
\hline
\end{tabular}

\section{CHOICE OF INVESTIGATION SITES}

The study site should be chosen randomly from a list of possible locations, using a standardized method. It could be also a rational choice according to criteria previously determined (considering environment, expertise of the health staff, accessibility of data, etc.), subject to specifying the reasons for this choice.

\section{Surveys in health centers}

Health center surveys use all documents filled out in health centers: registries of hospital consultations and hospitalizations, laboratory registries, case report forms, death records, etc.
Optionally, specific documents can be collected and analyzed. These surveys provide information on hospitalized patients who represent $40-60 \%$ of victims of venomous animals in most developing countries, particularly in Africa (1, 3, 12). For this reason, these measures are called hospital incidence, hospital mortality and hospital case fatality rate.

Retrospective surveys aim to use available data collected from the different registries completed by the nursing staff in charge of the management of venomous animal bites or stings, while prospective studies are documented by appropriate questionnaires prepared in advance according to research purposes.

The analysis and results are consistent with 
standard protocols for epidemiological studies. The incidence and mortality rates are usually expressed as number of cases per 100,000 inhabitants per year.

\section{Household and community surveys}

Households and communities are surveyed on the basis of standardized questionnaires, administered to community members, that also include questions on the bites or stings that occurred in the entourage of the questioned person during a given period: number of cases, deaths, name of victims (to eliminate duplicates from one household to another as they are often related), age at the time of the accident, season (if possible the date of the accident) and circumstances of the accident (location and activity of the victim at the time of the accident), time of day (if possible the exact time), site of the bite or sting, main symptoms, treatment, clinical progression, and outcome.

Household surveys should define in advance the proportion of respondents compared to the reference population, depending on the expected representativeness and the financial and human resources available. The choice of surveyed locations and investigation procedures should also be defined in advance. Care should be taken to note the number of inhabitants and the number of persons belonging to each of the communities surveyed. Finally, the age of the respondents will be noted.

Investigations at demographic sites generally follow a protocol defined by site administrators, especially with regard to the questioned persons and questions. An advantage of such surveys is that many other data collected routinely could be used and cross-referenced.

Different basic indicators are:

\section{Health personnel}

These surveys aim to assess the behavior of health personnel in charge of managing accidents due to venomous animals. The questionnaire are administered and analyzed taking into account local practices: level of health centers and personnel, services involved required by the management of people bitten or sting by venomous animals, known specific problems (equipment of health centers, state of the cold chain) etc.

Knowledge of the incidence and mortality of accidents due to venomous animals is necessary for the management of these events by health services (13). In particular, it should specify the geographic distribution and specific local requirements for equipment, symptomatic and adjuvant drugs, and antivenoms. The ideal would be to use the data centralized by the health authorities. But they are often inaccessible or confusing: in many cases, all accidents are aggregated to consider all animal attacks without differentiating the species responsible (crocodile, buffalo or elephant attacks, etc.), domestic animal bites (for rabies), envenomations or allergic responses, including those from hymenoptera. Moreover, even if efforts are made to identify the attackers, the data are often incomplete or unreliable.

Therefore, it is necessary to rely on limited local surveys which require methodological rigor for data collection and analysis, in order to exploit useful information.

One important aspect, often overlooked, is the choice of the study location. Some places might skew the results and should be avoided: locations where the incidence is particularly high due to specific environmental conditions, medical team highly concerned with envenomation, reference

Incidence $=\frac{\text { Notified cases } \times 100,000}{\text { Years covered by the survey } \times \text { covered population }}=x$ cases $/ 100.000$ people/year
$\underline{\text { Mortality }}=\frac{\text { Notified deaths } \times 100,000}{\text { Years covered by the survey } \times \text { covered population }}=x$ deaths $/ 100.000$ people/year
$\underline{\text { Case Fatality Rate }=\frac{\text { Notified deaths } \times 100}{\text { Notified cases }}=x \text { deaths } / 100 \text { cases }}$


hospitals that treat few but severe cases transferred from peripheral health centers etc. The ideal would be to perform a random selection using a randomization technique based on a list of all health centers in the country or region of study. It is possible to stratify the choice based on criteria such as the level of health centers within the health pyramid, or such environmental conditions as climatic zones, vegetation, population density, economic or agricultural criteria etc.

Prospective surveys in health centers should be preferred to retrospective surveys, which are often less informative on clinical and biological data, treatment administered, clinical progression and outcome. Indicators should be designed before writing the protocol of the prospective survey in order to collect relevant data: delay of presentation, stage of edema, importance and location of bleeding sites, neurological symptoms, type and amount of antivenom administered, response to treatment, duration of hospitalization, clinical progression and outcome. All these data, generally absent from published studies, are relevant for assessing the severity of envenomation and treatment efficacy, and finally to ensure the improvement of the management of bites and stings by venomous animals.

Household surveys provide additional information essential because they relate to the general population and allow identification of at-risk populations, including those who reject modern medicine or who cannot benefit from it. Methodological rigor is particularly important for a reliable analysis. The most common causes of failure are absence or inaccuracy of the denominator, i.e. coverage period of the investigation and/or population covered by the survey. Very often, investigators limit the surveyed period to one or a few years. On the one hand, a short period reduces the information and secondly, it is very difficult for the interviewer and interviewee to understand one another as to the period, especially if the interviewee can remember the exact date of the accident, which is rare. In general, accidents caused by venomous animals leave a lasting impression, even if the victim does not remember all details, such as the date of occurrence. For example, a victim may refer to a bite or sting that occurred outside the period covered by the investigation either because he/she forgot the exact date, or because he/she wants to talk about it. As a consequence, the incidence will be exaggerated. It is rare that a victim forgets that he was bitten by a snake or stung by a scorpion, even if the event is very old. That is why it is best to question the person on the whole of his or her life, rather than on a limited period, in order to ascertain whether a reported bite or sting by a venomous animal dates back to a prior phase of the victim's life. Thus, the period covered by the survey correspond to his/her age and finally to the mean age of all respondents. In addition, it is important to refer to the population covered by the interrogation, i.e. the number of persons belonging to interviewed households, which corresponds to all the villagers if the survey is exhaustive or only the members of interviewed households in the case of a partial survey.

Thus, the formulas of the incidence and mortality become:

$$
\begin{aligned}
& \text { Mortality }=\frac{\text { Notified deaths } \times 100,000}{\text { Mean age of questioned individuals } \mathrm{x} \text { covered population }}=x \text { deaths } / 100.000 \text { people/year } \\
& \underline{\text { Incidence }}=\frac{\text { Notified cases } \times 100,000}{\text { Mean age of questioned individuals } x \text { covered population }}=x \text { cases } / 100.000 \text { people } / \text { year }
\end{aligned}
$$

However, in this case, the incidence includes asymptomatic bites or stings and mild or severe envenomation $(1,3,11,14)$.

One method of verifying the incidence among respondents is to calculate it according to the following formula:

$$
\underline{\text { Incidence }}=\frac{\text { Notified cases in questioned individuals } \times 100.000}{\text { Mean age of questioned individuals } \mathrm{x} \text { number questioned individuals }}=x \text { cases } / 100,000 \text { people/year }
$$


When the incidence is high, both incidences are similar.

Different surveys in the same area using several independent methods have shown the robustness of the method and reliability and accuracy of the results (5-10).

\section{CONCLUSION}

Pending the availability of an effective notification of cases, health authorities can take steps to improve the management of bites and stings from venomous animals on the basis of well distributed and correctly executed surveys. They can anticipate the demand for antivenoms and symptomatic drugs so that they can be distributed in advance where they are needed.

In addition, household surveys provide relevant information on the treatment-seeking behavior of victims of bites or stings by venomous animals, and precisely identify the actual population at risk who must enter the modern care system to get the best treatment.

\section{COPYRIGHT}

\section{(C) CEVAP 2012}

\section{SUBMISSION STATUS}

Received: September 26, 2012.

Accepted: October 30, 2012.

Abstract published online: November 9, 2012.

Full paper published online: November 30, 2012.

\section{CONFLICTS OF INTEREST}

The authors declare no conflicts of interest.

\section{CORRESPONDENCE TO}

Jean-Philippe Chippaux, UMR 216, IRD, 08 BP 841, Cotonou, Bénin. Phone: +229 94345110. Email: jean-philippe.chippaux@ird.fr.

\section{REFERENCES}

1. Chippaux JP. Snake-bites: appraisal of the global situation. Bull World Health Organ. 1998;76(5):51524.

2. Kasturiratne A, Wickremasinghe AR, de Silva N, Gunawardena NK, Pathmeswaran A, Premaratna $\mathrm{R}$, et al. The global burden of snakebite: a literature analysis and modeling based on regional estimates of envenoming and deaths. PLoS Med. 2008;5(11)e218.

3. Chippaux JP. Estimate of the burden of snakebites in sub-Saharan Africa: a meta-analytic approach. Toxicon 2011;57(4):586-99.

4. Chippaux JP. Epidemiology of snakebites in Europe: a systematic review of the literature. Toxicon. 2012;59(1):86-99.

5. Chippaux JP. Epidémiologie des morsures de serpent en République de Côte d'Ivoire. Bull Soc Pathol Exot. 2002;95(3):167-71.

6. Chippaux JP. Epidémiologie des morsures de serpent au Bénin. Bull Soc Pathol Exot. 2002;95(3):172-4.

7. Chippaux JP, Diallo A. Evaluation de l'incidence des morsures de serpent en zone de sahel sénégalais, l'exemple de Niakhar. Bull Soc Pathol Exot. 2002;95(3):151-3.

8. Guyavarch E, Trape JF. L'incidence des morsures de serpents en zone rurale au Sénégal oriental. Bull Soc Pathol Exot. 2005;98(3):197-200.

9. Chippaux JP, Vieillefosse S, Sall O, Mafouta R, Diallo A. Evaluation de l'incidence des morsures de serpent au Sénégal. Bull Soc Pathol Exot. 2005;98(4):277-82.

10. Guyavarch E, Chippaux JP. Mesurer l'incidence des morsures de serpent : méthodologie d'enquête auprès des ménages (l'exemple de Bandafassi, Sénégal). Bull Soc Pathol Exot. 2005;98(4):269-72.

11. Guyavarch E, Pison G, Duthé G, Marra A, Chippaux JP. La mortalité violente dans trois régions rurales du Sénégal. Eur J Pop. 2010;26(4):483-505.

12. Chippaux JP. Snakebite in Africa: current situation and urgent needs. In: Mackessy SP, editor. Reptile venoms and toxins. Boca Raton: Taylor \& Francis/CRC Press; 2009. p. 445-65.

13. Chippaux JP. Estimating the global burden of snakebite can help to improve management. PLoS Med. 2008;5(11):e221.

14. ChippauxJP, Goyffon M. Epidemiology of scorpionism: a global appraisal. Acta Trop. 2008;107(2):71-9. 